\title{
Crystal structure of sodium ytterbium(III) selenide, $\mathrm{NaYbSe}_{2}$
}

\author{
A. K. Gray, B. R. Martin and P. K. Dorhout* \\ Colorado State University, Department of Chemistry, Fort Collins, CO 80523, USA
}

Received December 4, 2002, accepted and available on-line December 20, 2002; CSD-No. 409678

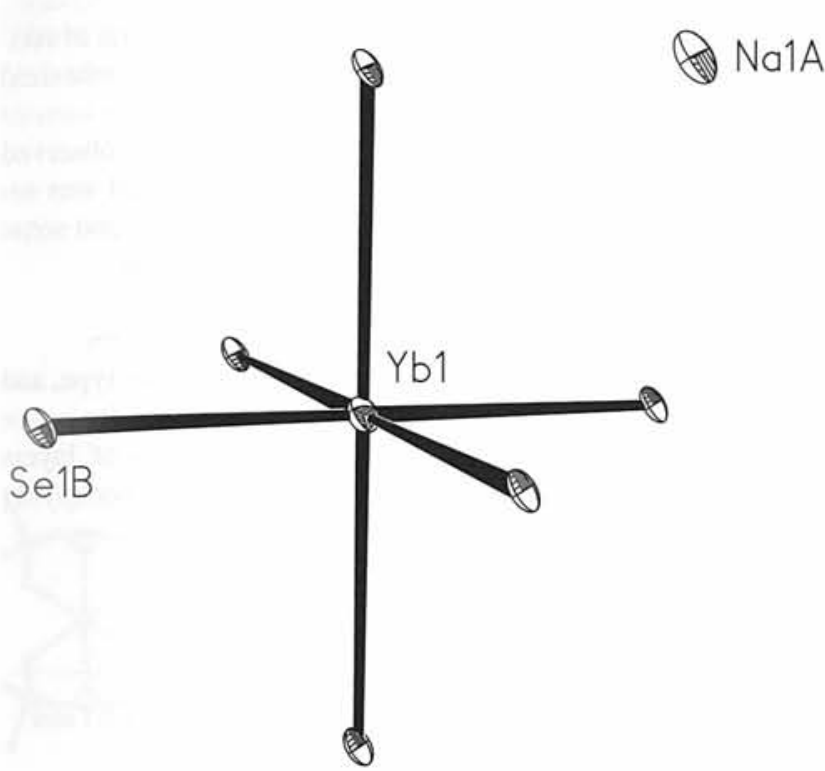

Abstract

$\mathrm{NaSe}_{2} \mathrm{Yb}$, trigonal, $R \overline{3} m$ (No. 166), $a=4.0568(8) \AA$, $c=20.772(6) \AA, V=296.1 \AA^{3}, Z=3, R_{\mathrm{gt}}(F)=0.051$, $w R_{\text {ref }}\left(F^{2}\right)=0.110, T=298 \mathrm{~K}$.

\section{Source of material}

Crystals of $\mathrm{NaYbSe}_{2}$ were formed from a molten chalcogenide flux reaction of $51.5 \mathrm{mg} \mathrm{Yb}, 21.8 \mathrm{mg} \mathrm{Ge}, 94.0 \mathrm{mg} \mathrm{Se}$, and $40.6 \mathrm{mg}$ $\mathrm{Na}_{2} \mathrm{Se}_{2}$. The reactants were combined in a fused silica ampoule in an inert atomosphere glovebox, sealed under vacuum, and heated to $998 \mathrm{~K}$ at a rate of $35 \mathrm{~K} /$ hour. After 72 hours of heating, the ampoule was cooled at $4 \mathrm{~K}$ / hour to room temperature. Dimethylformamide was added to dissolve remaining sodium selenide flux, resulting in well-formed hexagonal red-orange plates of $\mathrm{NaYbSe}_{2}$.

\section{Experimental details}

Quantitative energy dispersive spectroscopy yielded atomic ratios 26(3) at \% Na, O(0) at\% Ge, 47(5) at\% Se and 27(4) at\% Yb. The errors are associated with surface contamination, resulting from washing the residual flux from the crystals, and represent measurements taken from many positions on several crystals. Germanium (not contained in the title compound) was involved in the formation of various sodium germanium selenides.

$\mathrm{X}$-ray intensity data was collected from a relatively thin plate, resulting in a small systematic absorption error after empirical absorption correction.

\section{Discussion}

$\mathrm{NaYbSe} 2$ crystallizes in the $\mathrm{NaFeO}_{2}$ structure type, and is isostructural to the family $\mathrm{ALnX}_{2}, \mathrm{~A}=$ alkali metal, $\mathrm{Ln}=$ rare earth element, $X=S, S e$ [1]. The structure consits of layers of octahedrally coordinated $\mathrm{Yb}$ surrounded by Se, with Na occupying the interlayer sites.

Table 1. Data collection and handling.

$\begin{array}{ll}\text { Crystal: } & \text { red-orange plate, size } 0.01 \times 0.1 \times 0.15 \mathrm{~mm} \\ \text { Wavelength: } & \text { Mo } K_{\alpha} \text { radiation }(0.71073 \AA) \\ \mu: & 139.96 \mathrm{~cm}^{-1} \\ \text { Diffractometer, scan mode: } & \text { Bruker SMART CCD; } 1800 \text { frames, } \varphi=0^{\circ}, \\ & 120^{\circ}, 240^{\circ} ; \Delta \omega=0.3^{\circ} \\ 2 \theta_{\text {max }}: & 45.88^{\circ} \\ N(h k l)_{\text {measured }}, N(h k l)_{\text {unique }}: & 609,70 \\ \text { Criterion for } I_{\text {obs }}, N(h k l)_{\text {gt }}: & I_{\text {obs }}>2 \sigma\left(I_{\text {obs }}\right), 69 \\ N(\text { param })_{\text {refined }} & 9 \\ \text { Programs: } & \text { SHELXTL [2], SADABS [3] }\end{array}$

Acknowledgments. This research was funded by the National Science Foundation grant \# CHE-0076180. The authors acknowledge S. M. Miller for crystallographic help.

\section{References}

1. Bronger, W.; Brüggemann, W.; von der Ahe, M.; Schmitz, D.: Zur Synthese und Struktur ternärer Chalcogenide der Seltenen Erden $\mathrm{ALnX}_{2}$ mit $\mathrm{A}=$ Alkalimetall und $\mathrm{X}=$ Schwefel, Selen oder Tellur. J. Alloys Compds. 200 (1993) 205-210.

2. Bruker SHELXTL. Structure Determination Programs. Version 5.1, Bruker AXS, Inc., Madison, Wisconsin, USA 1998.

3. Sheldrick, G. M.: SADABS. Program for Empirical Absorption Correction of Area Detector Data. University of Göttingen, Germany 2000.

Table 2. Atomic coordinates and displacement parameters (in $\AA^{2}$ ).

\begin{tabular}{lllllllllll} 
Atom & Site & $x$ & $y$ & $z$ & $U_{11}$ & $U_{22}$ & $U_{33}$ & $U_{12}$ & $U_{13}$ & \\
$\mathrm{Na}(1)$ & $3 a$ & 0 & 0 & 0 & $0.025(8)$ & $U_{11}$ & $0.01(1)$ & $U_{11} / 2$ & 0 & 0 \\
$\mathrm{Yb}(1)$ & $3 b$ & 0 & 0 & $1 / 2$ & $0.010(2)$ & $U_{11}$ & $0.005(2)$ & $U_{11} / 2$ & 0 \\
$\mathrm{Se}(1)$ & $6 c$ & 0 & 0 & $0.2424(2)$ & $0.012(2)$ & $U_{11}$ & $0.003(2)$ & $U_{11} / 2$ & 0 & 0 \\
\hline
\end{tabular}

\footnotetext{
* Correspondence author (e-mail: pkd@lamar.colostate.edu)
} 